\title{
Sensitivity of Natural GAS HCCl Combustion to Fuel and Operating Parameters Using Detailed Kinetic Modeling
}

D. Flowers, S. Aceves, C.K. Westbrook, J.R. Smith, R. Dibble

This article was submitted to

American Society of Mechanical Engineers International Mechanical Engineering Congress and Exposition, Nashville, TN, November 1419, 1999

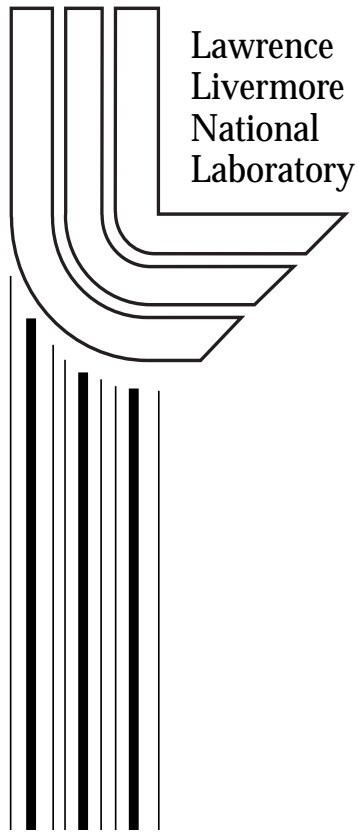

July 19, 1999 


\section{DISCLAIMER}

This document was prepared as an account of work sponsored by an agency of the United States Government. Neither the United States Government nor the University of California nor any of their employees, makes any warranty, express or implied, or assumes any legal liability or responsibility for the accuracy, completeness, or usefulness of any information, apparatus, product, or process disclosed, or represents that its use would not infringe privately owned rights. Reference herein to any specific commercial product, process, or service by trade name, trademark, manufacturer, or otherwise, does not necessarily constitute or imply its endorsement, recommendation, or favoring by the United States Government or the University of California. The views and opinions of authors expressed herein do not necessarily state or reflect those of the United States Government or the University of California, and shall not be used for advertising or product endorsement purposes.

This is a preprint of a paper intended for publication in a journal or proceedings. Since changes may be made before publication, this preprint is made available with the understanding that it will not be cited or reproduced without the permission of the author.

This report has been reproduced

directly from the best available copy.

Available to DOE and DOE contractors from the

Office of Scientific and Technical Information

P.O. Box 62, Oak Ridge, TN 37831

Prices available from (423) 576-8401

http://apollo.osti.gov/bridge/

Available to the public from the

National Technical Information Service

U.S. Department of Commerce

5285 Port Royal Rd.,

Springfield, VA 22161

http://www.ntis.gov/

OR

Lawrence Livermore National Laboratory

Technical Information Department's Digital Library

http://www.llnl.gov/tid/Library.html 


\title{
SENSITIVITY OF NATURAL GAS HCCI COMBUSTION TO FUEL AND OPERATING PARAMETERS USING DETAILED KINETIC MODELING
}

\author{
Daniel Flowers, Salvador Aceves, Charles K. Westbrook, J. Ray Smith \\ Lawrence Livermore National Laboratory
}

\author{
Robert Dibble \\ University of California, Berkeley
}

\begin{abstract}
This paper uses the HCT (Hydrodynamics, Chemistry and Transport) chemical kinetics code to analyze natural gas $\mathrm{HCCI}$ combustion in an engine. The HCT code has been modified to better represent the conditions existing inside an engine, including a wall heat transfer correlation. Combustion control and low power output per displacement remain as two of the biggest challenges to obtaining satisfactory performance out of an HCCI engine, and these are addressed in this paper.

The paper considers the effect of natural gas composition on HCCI combustion, and then explores three control strategies for HCCI engines: DME (dimethyl ether) addition, intake heating and hot EGR addition. The results show that HCCI combustion is sensitive to natural gas composition, and an active control may be required to compensate for possible changes in composition. The three control strategies being considered have a significant effect in changing the combustion parameters for the engine, and should be able to control HCCI combustion.
\end{abstract}

\section{INTRODUCTION}

Homogeneous Charge Compression Ignition (HCCI) engines are being considered as a future replacement for diesel engines. HCCI engines have the potential for high efficiency (diesel-like; Suzuki et al., 1997), very low nitrogen oxide $\left(\mathrm{NO}_{\mathrm{x}}\right)$ and particulate emissions, and low cost (because no high-pressure injection system is required). Disadvantages of HCCI engines are: high hydrocarbon (HC) and carbon monoxide (CO) emissions, high peak pressures, high rates of heat release, reduced operating range, low maximum power, difficulty in starting the engine, and difficulty of control.
HCCI was identified as a distinct combustion phenomenon about 20 years ago. Initial papers (Onishi et al., 1979; Noguchi et al., 1979) recognized the basic characteristics of HCCI that have been validated many times since then: HCCI ignition occurs at many points simultaneously, with no flame propagation. Combustion was described as very smooth, with very low cyclic variations. Noguchi et al. (1979) also conducted a spectroscopic study of HCCI combustion. Many radicals were observed, and they were shown to appear in a specific sequence. In contrast, with spark-ignited (SI) combustion all radicals appear at the same time (probably distributed in the same sequence through the flame front). These initial experiments were done in 2-stroke engines, with very high rates of EGR.

Since then, HCCI two-stroke engines have been developed to the point of commercialization for motorcycles (Ishibashi and Asai, 1996). HCCI motorcycle engines have higher fuel economy, lower emissions and smoother combustion than 2-stroke spark-ignited engines. However, $\mathrm{HC}$ and $\mathrm{CO}$ emissions out of the $\mathrm{HCCI}$ engine are still very high compared with the current automotive emissions standards. An improved version of the engine has been recently evaluated (Ishibashi and Asai, 1998), which shows improvements in fuel economy and emissions.

Najt and Foster (1983) did the first HCCI experiment with a four-stroke engine. They also analyzed the process, considering that HCCI is controlled by chemical kinetics, with no influence from physical effects (turbulence, mixing). Najt and Foster used a simplified chemical kinetics model to predict heat release as a function of pressure, temperature, and species concentration in the cylinder.

Since then, a description of the HCCI process has gained acceptance. HCCI has been described as purely controlled by 
chemical kinetics, with little effect of turbulence. Crevices and boundary layers are too cold to react, and result in hydrocarbon and $\mathrm{CO}$ emissions. Combustion at homogeneous, low equivalence ratio conditions results in modest temperature combustion products, which do not generate $\mathrm{NO}_{\mathrm{x}}$ or particulate matter.

Physical understanding has not resulted in a solution to the problems of operating a four-stroke engine in HCCI mode. The control issue appears to be most important. Some alternatives have been described (Smith et al., 1997; Willand et al., 1998), but further work is required to identify a general control strategy.

Analysis of HCCI engines is not well developed, even though the process may be reasonably well understood. Most publications on HCCI present only experimental results. Of those that present analysis, some have used a fluid mechanics code (KIVA, Amsden, 1993) with a very simplified chemical kinetics model. The use of fluid mechanics codes is appropriate in operating conditions such as PREDIC (early direct injection; Miyamoto et al., 1999), where the charge is not homogeneous and fuel mixing and evaporation may have a significant effect in the combustion process. For homogeneous charge engines, the process is mainly dominated by chemistry, and it is more important to have a detailed chemical kinetics model than a fluid mechanics model. Therefore, valuable predictions and results can be obtained from single-zone chemical kinetics analyses that assume that the combustion chamber is a well-stirred reactor with uniform temperature and pressure (Christensen et al., 1998; Aceves et al., 1999). This is the tool used in this paper. The ideal tool for HCCI analysis is a combination of a fluid mechanics code with a detailed chemical kinetics code. This is, however, well beyond our current computational capabilities.

The concept considered here is a high compression ratio, lean burn, natural gas engine with homogeneous charge compression ignition (HCCI). This engine has the potential to achieve high efficiency and very low $\mathrm{NO}_{\mathrm{x}}$ emission. The key to achieving this potential is developing control methods that allow for consistent operation over the range of operating conditions. Because HCCI combustion is an autoignition process, the heat release occurs very rapidly. The major factors that contribute to the initiation of this autoignition process in an engine cycle are pressure, temperature, fuel composition, equivalence ratio, and engine speed. These factors are influence by many operating parameters such as inlet heating, supercharging, and residual gas trapping. The control methods must be designed to tune the heat release process to occur at the appropriate time in the engine cycle.

\section{MODELING OF THE HCCI COMBUSTION PROCESS}

A zero-dimensional detailed kinetic model is used here to model HCCI combustion. A premixed charge at uniform temperature and pressure is subjected to a change in cylinder volume that depends on the engine speed and geometry. This kind of model cannot capture the multi-dimensional processes that occur in a real engine cylinder, but, since the heat release is a global non-propagating autoignition process, a zero-dimensional model can reasonably capture the start of combustion and heat release of the core mixture. Since the start of combustion of the central core dictates the overall process, control of this combustion timing will control performance.

All of the modeling computations in this study were carried out using the HCT model (Hydrodynamics, Chemistry and Transport; Lund, 1978). This model has been used in a large number of investigations over the years, and in particular was used in past studies of engine knock and autoignition (Westbrook, et al., 1991; Pitz et al., 1991, Westbrook et al., 1988). The HCT code permits the use of a variety of boundary and initial conditions for reactive systems, depending on the needs of the particular system being examined. In the present case, the relevant conditions are those which describe the bulk gases in the combustion chamber.

Autoignition of a homogeneous charge is virtually identical to the knock process that can occur in the Otto cycle engine. From detailed kinetic modeling of motored engines using a homogeneous charge of a variety of fuels, it is known that the controlling parameters in the initiation of this process are the fuel components (mixtures behave differently than neat fuels), and the temperature and density history that the fuel air mixture experiences. Motored engine experiments at General Motors Research Laboratories (Curran et al., 1995, Pitz et al., 1991) agree well with HCT simulation of this process. Thus if the precise conditions at the start of compression are known (species, temperature and pressure), the beginning of combustion can be accurately predicted.

During an engine cycle, a number of processes occur which influence the time variation of the temperature and pressure of the bulk reactive gases in the combustion chamber. Piston motion first compresses and heats the bulk gases and then expands and cools them. During this time chemical reactions release heat and change the overall composition of the gases. Fresh unreacted fuel and air are added to hot residual gases left over from the previous cycle. Residual gases from previous engine cycles, which consist largely of water vapor, $\mathrm{CO}_{2}$, and molecular nitrogen and oxygen are assumed fully mixed with the fresh charge. In addition, heat losses to the engine chamber walls, blowby, fuel trapping in crevice volumes, and other processes occur. In the current simulations only heat transfer losses are taken into account.

The computational model treats the combustion chamber as a homogeneous reactor with a variable volume. The mixed temperature of the residual gases and the fresh charge is estimated by a published procedure (Heywood, 1988). The volume is changed with time using a slider-crank formula. The heat transfer submodel employed in the HCT code simulations uses Woschni's correlation (Woschni, 1967).

The present analysis considers a single zone, lumped model that ignores spatial variations in the combustion chamber, treating heat loss as a distributed heat transfer rate, proportional to the temperature difference between the average gas temperature and a time-averaged wall temperature. The authors recognize that this is a great oversimplification of the actual condition within the combustion chamber. In particular, the boundary layer, which contains significant mass, must be at a lower temperature than the bulk gas near TDC. Due to the assumed temperature uniformity our estimates of burn duration and the heat release processes, will be shorter than in experiments. That is, the boundary layer and crevices will always 
react last and extend the heat release rate compared to this simulation. Peak cylinder pressure and rate of pressure rise are thus overestimated with the current single-zone model, and the model cannot accurately predict $\mathrm{CO}$ and hydrocarbon emissions, which primarily depend on crevices. Predictions of start of combustion and $\mathrm{NO}$, which depend on the peak temperature of the core gases inside the cylinder, have been shown to be determined with reasonable accuracy (Aceves et al., 1999).

Two reaction mechanisms are used in this study. The first mechanism includes species through $\mathrm{C}_{4}$ (Curran et al. 1995), and models natural gas autoignition chemistry. The second mechanism is a reduced set with species through $\mathrm{C}_{2}$ and additionally including dimethyl ether (DME) oxidation chemistry (Curran et al. 1997). Both mechanisms include $\mathrm{NO}_{\mathrm{x}}$ kinetics from the Gas Research Institute mechanism version 1.2 (Frenklach et al., 1995). The chemical kinetic reaction mechanisms used by the model for methane ignition and $\mathrm{NO}_{\mathrm{x}}$ production have been extremely well established and are widely used.

The simulation is started at BDC where fresh charge at specified pressure, temperature and composition is inducted into the cylinder. If EGR is used, the proper fraction of major residual gas components is added. The cylinder wall, piston and head are all assumed to be at a uniform $430 \mathrm{~K}$. Chemical reactions are computed explicitly in the kinetics model. Thermodynamic table values of $c_{p}$ and $c_{v}$ are explicitly calculated to account for enthalpy and pressure changes. The simulation is stopped at BDC and the indicated efficiency is computed. The $\mathrm{NO}_{\mathrm{x}}$ values reported are taken at BDC.

\section{RESULTS}

Simulations have been performed to look at the effect of several different control parameters on HCCI combustion. One study uses the detailed natural gas chemistry model to look at the effect of natural gas composition on the peak of heat release in an HCCI engine. Because of the rapid heat release process peak of heat release typically occurs within 1-2 CAD of start of combustion. The effect of DME addition, inlet heating, and EGR has also been evaluated with respect to the control of combustion timing.

In these simulations the best operating point for an HCCI engine is taken to be peak heat release at TDC. Peak heat release prior to TDC results in lower efficiency, due to counterproductive early pressure rise, and higher $\mathrm{NO}_{\mathrm{x}}$ due to increasing peak temperatures with earlier combustion. Peak heat release after TDC reduces the effective compression ratio and the combustion efficiency. Previous experiments have shown that indicated thermal efficiency peaks when maximum heat release occurs close to TDC. This is shown in Figure 1, which has been adapted from the experimental results of Christensen et al. (1998). There is a potential to trade thermal efficiency and hydrocarbon emissions for greater power output. Combustion after TDC may allow for operation at higher equivalence ratios because the peak cylinder pressure is lower. This possibility is not considered here.

\section{Effect of Fuel Composition on Combustion Timing}

The HCT engine code has been used to assess the effect of variations in natural gas fuel composition on the start of combustion in an HCCI operated engine. The engine selected for these simulations is a $1.9 \mathrm{~L}$ engine based on the Volkswagen TDI. The TDI has a bore of $79.5 \mathrm{~mm}$ and a stroke of $95.5 \mathrm{~mm}$. The model engine has a compression ratio of 18 , and the absolute intake pressure is assumed equal to 2.0 bar. This engine has been selected because it is an appropriate geometry for a small vehicular engine, and will be studied in future experimental research.

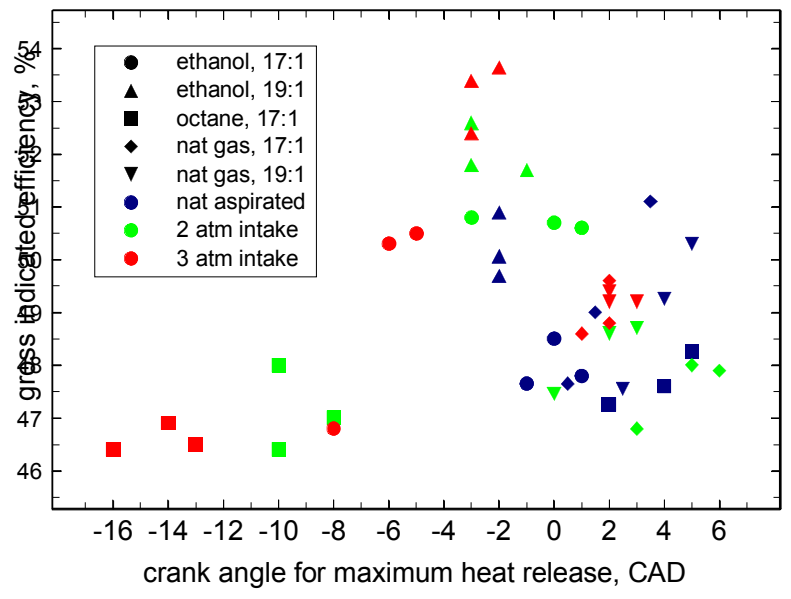
Figure 1 - Gross thermal efficiency versus timing for peak
heat release adapted from Lund Institute data
(Christensen et al., 1998).

These fuel sensitivity simulations compare crank angle for maximum heat release of a natural gas blend relative to a baseline blend operated in the same conditions. Because methane is the major component of natural gas, pure methane is the baseline fuel. The $\mathrm{BDC}$ temperature is adjusted so that the peak heat release of pure methane, for a given equivalence ratio and engine speed, occurs at TDC. The engine is run with no EGR or residual gas considered and the BDC temperature at the beginning of the expansion stroke is specified.

Figure 2 shows the results of methane combustion with maximum heat release at TDC for three equivalence ratios with varying engine speed. The figure shows that the BDC temperature for start of combustion must increase with increasing engine speed. The shorter reaction time available to achieve combustion at higher speeds makes it necessary to start the process at a higher temperature for peak heat release at TDC.

Natural gas is typically a mixture of methane, ethane, propane, and butane, as well as small amounts of other higher hydrocarbons and inert species (usually less than $1-2 \%$ by volume). Regional and seasonal factors play a significant role in the specific composition that a producer delivers. The Gas Research Institute studied the 
natural gas composition in the United States (Liss et al., 1992). Higher hydrocarbons in the fuel cause the autoignition process to start earlier than for pure methane. Low temperature reactions occur due to the higher hydrocarbons that do not occur in pure methane, causing additional charge heating and introduction of radicals well before TDC. In order to understand the effect of composition on the ignition process, several compositions of natural gas are tried and the advance of maximum heat release from TDC relative to pure methane combustion is determined using HCT. Using the Gas Research Institute data, several fuel blends have been selected that define a large range in composition. The natural gas is specified to consist only of the four primary components: methane, ethane, propane, and butane. Inert species are neglected as part of the composition because they add unnecessary complexity with little effect on the results. Also neglected are hydrocarbons higher than butane, which typically compose less than 0.1 mole percent of the gas composition. Table 1 presents the gas blends used for these studies.

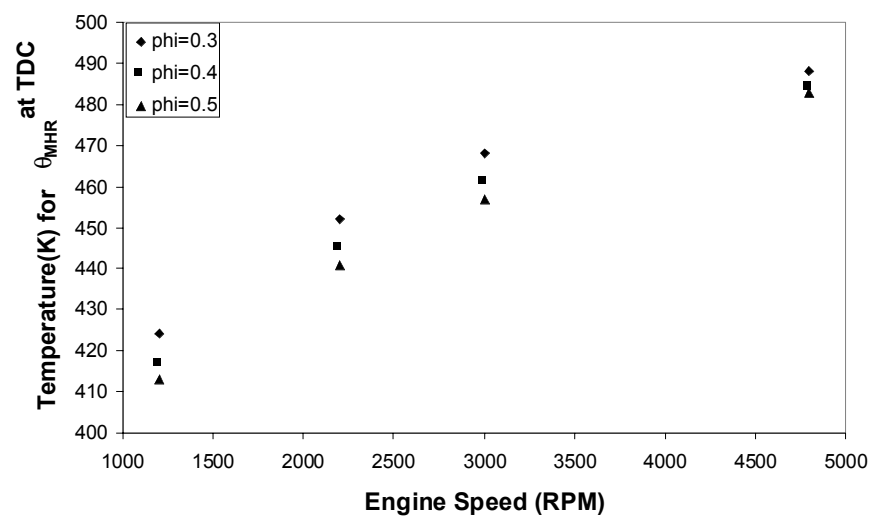

Figure 2 - Temperature for TDC peak heat release of pure methane versus engine speed

Figure 3 shows the advance in maximum heat release for the different natural gas blends. For a fixed equivalence ratio and engine speed the BDC temperature that results in maximum heat release at TDC for methane is determined. Using the methane BDC temperature the crank angle at which maximum heat release occurs for the different natural gas compositions is determined. The advance is plotted as a function of a figure of merit, which was found to collapse the data into a single curve. The figure of merit is calculated by scaling the mole fraction of ethane by a factor of $1 / 6$ and adding that to the mole fraction of propane and butane. This scaling implies that the dominant components resulting in early combustion are propane and butane. The twenty-three natural gas blends of table 1 have been evaluated at each of the three equivalence ratio/engine speed combinations. The important trend that these simulations show is the high sensitivity of heat release timing that can be seen for figures of merit up to 5 , a range that represents very typical blends delivered by gas suppliers.

A second study has been performed to determine what BDC temperature is required for different gas mixtures to achieve maximum heat release at TDC. Six blends from the previous twentythree have been selected as extremes in composition of each of the components as well as the overall blends. The reduction in BDC temperature with respect to methane required to achieve maximum heat release at TDC for each of the blends is shown in Figure 4, as a function of the same figure of merit used in Figure 3. The required temperature reduction is fairly consistent for the three cases.

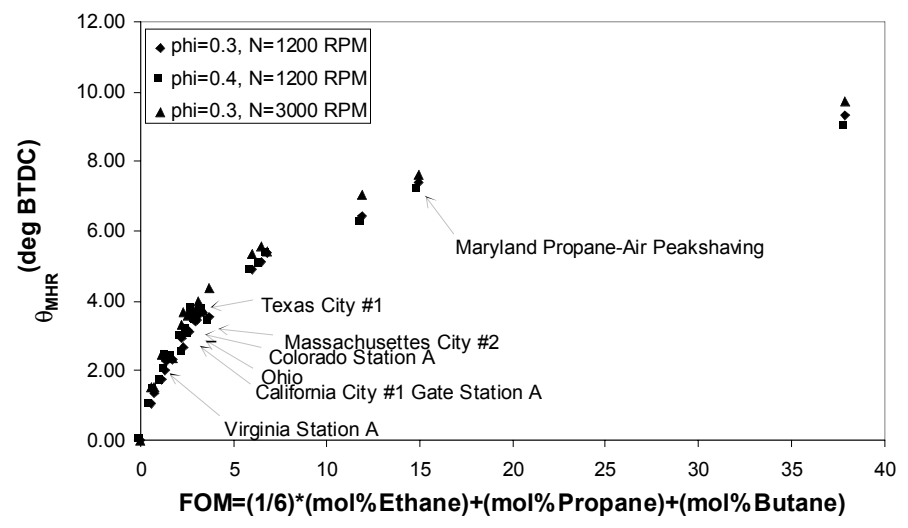

Figure 3 - Crank angle advance of peak heat release versus fuel composition figure of merit for fuel blends

Figures 3 and 4 indicate that compensation will be required to account for normal variations in fuel composition across the U. S., and a closed loop control system with an indicator of the timing of heat release may be necessary to account for these variations. It should be noted that the blends with the most advance are not typical and would likely occur only during "peak shaving" when a significant amount of propane is blended into the fuel during heavy natural gas use periods (Liss et al. 1992).

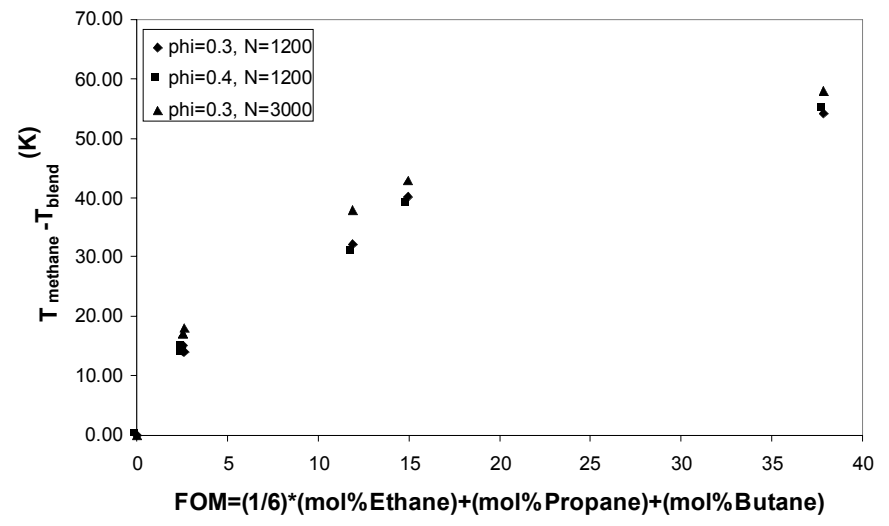

Figure 4 - Temperature for TDC peak heat release versus figure of merit for various fuel blends 


\section{Control Methods for HCCI Engines}

Three different methods of control have been studied for their ability to control combustion timing in HCCI engines: DME addition, intake heating, and EGR. The engine modeled in these simulations is a Cooperative Fuels Research engine with a bore of $82.5 \mathrm{~mm}$, a stroke of $114.3 \mathrm{~mm}$, and a connecting rod length of $254 \mathrm{~mm}$. Two compression ratios are considered: $12: 1$ and 18:1, with natural aspiration and 1 bar supercharge. Engine speed is fixed at $1800 \mathrm{rpm}$. The methane/DME reaction mechanism is used for these calculations. The control variable is adjusted so that the peak heat release always occurs at TDC. This engine and fuel have been selected to complement experimental research currently underway at UC Berkeley. Operating conditions have been selected based on experimental parameters. These results should always be taken as relative indicators of the performance of the engine with respect to the control parameters.

Operation of the engine is considered to be constrained by peak cylinder pressure and $\mathrm{NO}_{\mathrm{x}}$ emissions. The maximum peak cylinder pressure is set at 250 bar. This value is higher than the existing limit in most current engines. However, previous validation of the model has shown that single-zone HCT analysis overpredicts peak cylinder pressure, and it is therefore reasonable to use a high value as a limit (Aceves et al. 1999). The $\mathrm{NO}_{\mathrm{x}}$ emissions are restricted to $100 \mathrm{ppm}$. This limit would result in very low driving cycle emissions if the engine were used in an automobile.

Dimethyl Ether Additive Control. The additive control concept presented here is that the autoignition timing may be controllable by blending low cetane number fuel (natural gas) with high cetane number fuel (DME). Dimethyl ether is an ideal fuel additive for natural gas HCCI because has a short ignition delay, and because DME has similar reaction chemistry to methane and does not tend to promote soot formation.

Figure 5 shows the results for the addition of DME to the engine. DME fraction in the fuel, indicated efficiency, indicated mean effective pressure, peak cylinder pressure, and $\mathrm{NO}_{\mathrm{x}}$ are plotted versus intake equivalence ratio for the four different conditions. DME concentration is always adjusted to achieve peak heat release at TDC. Residual gases are not considered in this analysis so the charge is pure fuel and air and therefore the intake equivalence ratio is equal to the in-cylinder equivalence ratio. The inlet temperature is fixed at $333 \mathrm{~K}$ for each case except for the naturally aspirated 12:1 compression ratio. In that case the inlet temperature is increased to $400 \mathrm{~K}$ because complete combustion could not be achieved for the range of equivalence ratio without some inlet heating. Complete combustion refers to having a significant fraction (say $80 \%$ ) of the fuel burned. In practice it is very easy to determine complete combustion in the single zone model because either very little fuel reacts or nearly all reacts. The equivalence ratio reported includes both DME and methane. Complete combustion could not be achieved for the 12:1 compression ratio cases with equivalence ratio below 0.3 , and could not be achieved for the 18:1 compression ratio cases below equivalence ratio of 0.25 .
The maximum values of the performance variables achievable during operation may be constrained by peak cylinder pressure and a specified limit on $\mathrm{NO}_{\mathrm{x}}$. As Figure 5 shows, only the supercharged 18:1 compression ratio case approaches the 250 bar peak pressure limit. In all the cases analyzed, the $\mathrm{NO}_{\mathrm{x}}$ threshold is the governing constraint. If greater intake boost is used the pressure limit will likely play a stronger role. The $\mathrm{NO}_{\mathrm{x}}$ constraint limits both naturally aspirated cases and the supercharged 18:1 compression ratio case to an equivalence ratio of 0.4 , while the maximum equivalence ratio of the supercharged 12:1 compression ratio case is roughly 0.43 . The DME fraction required for the 12:1 cases ranges from slightly over $50 \%$ at low load to $30-35 \%$ at high load. For 18:1 compression ratio, the naturally aspirated engine requires 50\% DME at low load to $30 \%$ at high load, and the supercharged engine requires $25 \%$ at low load to $15 \%$ at high load.
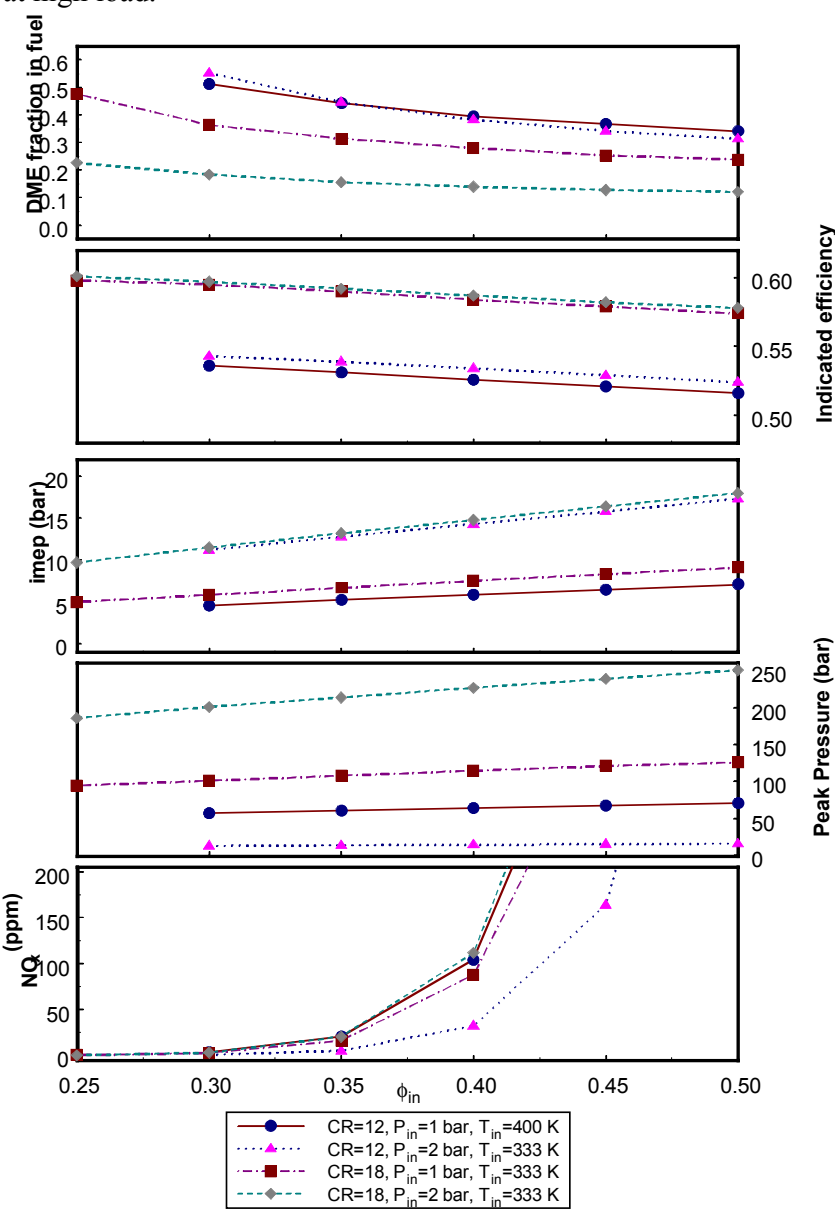

Figure 5 - Simulation results for $\mathrm{HCCl}$ control by DME

The indicated efficiencies range from $58 \%$ to $60 \%$ for $18: 1$ compression ratio, and from $52 \%$ to $54 \%$ for the $12: 1$ compression ratio cases. The indicated efficiency decreases with increasing equivalence ratio due to decreasing specific heat ratio and increasing heat transfer as the equivalence ratio increases. These efficiency 
results indicate the potential for high efficiency operation of HCCI engines.

The imep, in the allowable range of operation, ranges from 10 to 15 bar for the 18:1 compression ratio supercharged case, and from 11 to 15 bar for the 12:1 compression ratio supercharged case. For the 18:1 compression ratio naturally aspirated case the imep ranges from 5 to 7.5 bar, and ranges from 5 to 6 bar for the 12:1 compression ratio naturally aspirated case. The naturally aspirated maximum imep results are fairly low, and indicate that supercharging is necessary to increase the power density. Because the lowest calculated imep achievable in this control method is 5 bar, throttling may be required to for idle operation, to balance a typical 1-2 bar frictional loss at these conditions (Heywood, 1988).

Inlet heating Control. HCCI control by inlet heating involves adjusting the mixture temperature so that conditions are appropriate for autoignition of the charge to occur at the desired crank angle. A heat source, such as an electric heater or air-to-air heat exchanger with hot exhaust gases would be required in an operating engine. Figure 6 shows inlet temperature, indicated efficiency, imep, peak pressure, and $\mathrm{NO}_{\mathrm{x}}$ plotted versus equivalence ratio for the CFR engine operated with inlet heating to obtain maximum heat release at TDC. The mixture at the start of the cycle is fuel and air only with no residual gases considered. The inlet temperature is the temperature specified in the cylinder at beginning of the compression stroke.

The 250 bar pressure constraint is not approached in any of the simulations. The $100 \mathrm{ppm} \mathrm{NO}_{\mathrm{x}}$ constraint is reached at equivalence ratios of 0.31 to 0.32 for all cases. This $\mathrm{NO}_{\mathrm{x}}$ limit could probably be extended with some EGR, at the expense of efficiency. Supercharging and increasing the compression ratio decreases the required inlet heating and this appears to also reduce the peak temperature at a fixed equivalence ratio, leading to lower $\mathrm{NO}_{\mathrm{x}}$ for these cases. For the 12:1 compression ratio naturally aspirated engine the simulation results indicate temperatures of about $550 \mathrm{~K}$ to obtain combustion at TDC. Supercharging a 12:1 compression ratio engine reduces the required temperature down to the range of 525 to $540 \mathrm{~K}$. For the 18:1 compression ratio naturally aspirated case the inlet temperature required for TDC combustion is in the range of 465 to $470 \mathrm{~K}$, and for the $18: 1$ supercharged case the inlet temperature range is 435 to $450 \mathrm{~K}$. With inlet heating, autoignition can be achieved even at very low equivalence ratio. Compression heats the intake air, so that little additional heating may be required under some supercharged conditions. It should also be noted that, in some cases, increasing the equivalence ratio requires higher temperatures to achieve TDC peak heat release, due to decreasing specific heat ratio and chemistry effects.

The indicated efficiency ranges from $55 \%$ to $60 \%$ for the $18: 1$ compression ratio cases and from $49 \%$ to $54 \%$ for the $12: 1$ compression ratio cases, with the two supercharged cases having slightly higher efficiency over most of the range than the respective naturally aspirated cases. Again, these efficiency results demonstrate the potential for very high efficiency in an HCCI engine.
For the constrained range of operation, the imep ranges from 3 to 8 bar for the supercharged 18:1 compression ratio, 1.3 to 4 bar for the naturally aspirated $18: 1$ compression ratio, 2 to 6 bar for the supercharged 12:1 compression ratio, and 1 to 3 bar for the naturally aspirated 12:1 compression ratio. The peak numbers suggest that even more supercharging may be required to achieve reasonable power density out of a lean HCCI engine. This could lead to the peak cylinder pressure being the dominant constraint. The low-load imep results show that frictional work can be balanced by the combustion work without throttling.

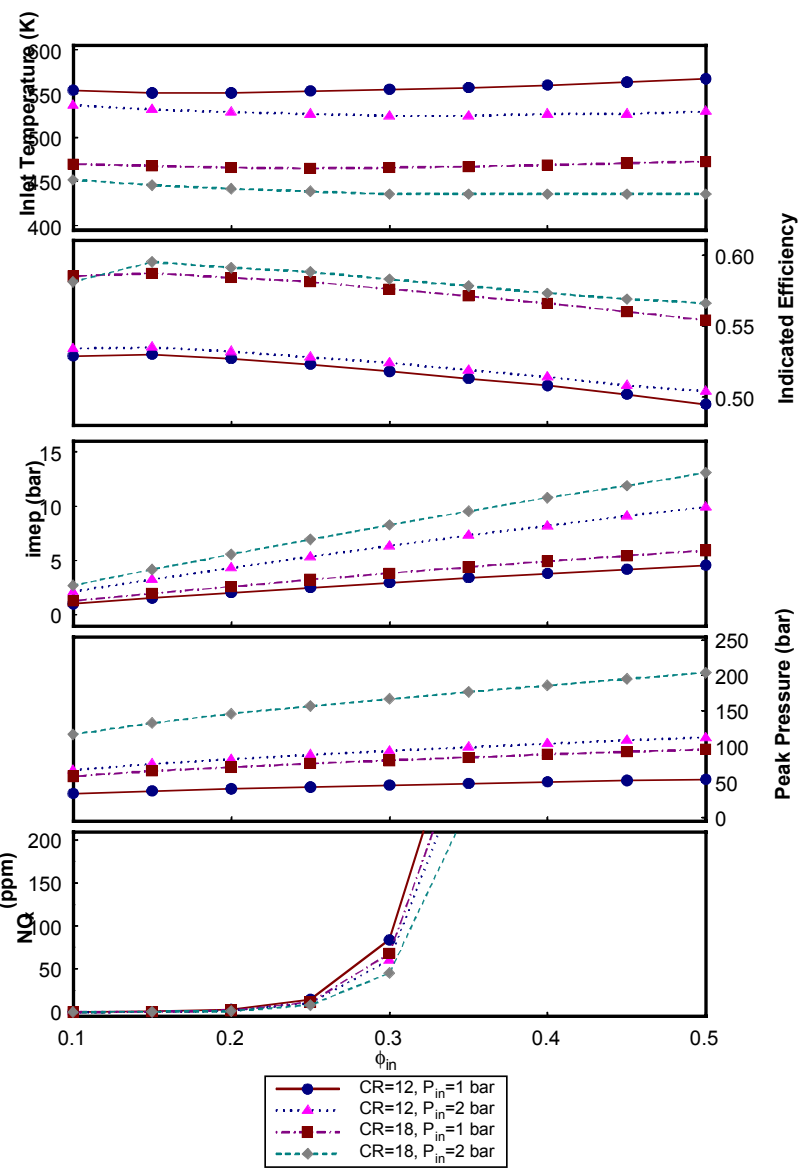

Figure 6 - Simulation results for $\mathrm{HCCl}$ control by intake heating

EGR Control. Blending the intake fuel-air mixture with hot residual gases has several effects. First, the residual gases will raise the charge temperature. Second, the specific heat ratio of the mixture will decrease resulting in lower TDC temperature and pressure relative to a pure fuel/air mixture. Lastly, because this is a lean burn process, the in-cylinder fuel-air ratio will be leaner than the intake fuel-air ratio by the relationship

$$
\phi_{\text {act }}=\frac{1-E G R}{1-E G R ? \phi_{\text {in }}} \phi_{\text {in }}
$$


where EGR is the fraction of residual gas in the charge, $\phi_{\text {in }}$ is the intake equivalence ratio, and $\phi_{\text {act }}$ is the in-cylinder equivalence ratio. In an operating engine hot residual gases can be introduced into the cylinder in several ways. For example, an insulated line could be run from the exhaust and blended with the intake air or the engine exhaust valve could be closed early with variable valve timing control.

Figure 7 shows the EGR fraction, indicated efficiency, imep, peak cylinder pressure, and $\mathrm{NO}_{\mathrm{x}}$ plotted versus the in-cylinder equivalence ratio. The maximum cylinder pressure constraint is not met in either of these cases. The $\mathrm{NO}_{\mathrm{x}}$ limit governs the operation range. The maximum equivalence ratio allowable based on the $\mathrm{NO}_{\mathrm{x}}$ constraint ranges between 0.5 for the naturally aspirated 12:1 compression ratio and 0.39 for the supercharged 18:1 compression ratio. The lower $\mathrm{NO}_{\mathrm{x}}$ emissions for a given equivalence ratio compared with the results for preheated intake (Figure 6) are due to the higher specific heat of the residual gases, which limits the peak cylinder temperature. The EGR fraction required for TDC peak heat release decreases with supercharging and increased compression ratio. The EGR fraction ranges from $60 \%$ for low load in the naturally aspirated $12: 1$ case to $26 \%$ in the $18: 1$ case at high load. The left-hand end of each curve on the EGR fraction versus equivalence ratio plot is the lowest equivalence ratio at which complete combustion at TDC could be achieved. The lower operating limit goes to lower equivalence ratio with supercharging and increasing compression ratio.

Indicated efficiency is higher than $49 \%$ in all cases, and reaches $58 \%$ for the supercharged 18:1 case. The imep ranges from 2 to 2.5 bar for the naturally aspirated 12:1 compression ratio, from 5 to 6 bar for the supercharged 12:1 compression ratio, from 3 to 3.7 bar for the naturally aspirated 18:1 compression ratio, and from 6 to 8 bar for the supercharged 18:1 compression ratio. Further supercharging or relaxation of the $\mathrm{NO}_{\mathrm{x}}$ limit at peak load may be necessary to achieve reasonable power density. The low-load imep results indicate that some throttling may be necessary for idle operation.

Discussion of Control Methods. Each of the control methods analyzed in this paper has the potential to control combustion timing in an HCCI engine. Some general observations can be made about how these methods can be applied to HCCI engine control. Supercharging will be required to achieve reasonable power density. The intake air compression method, either with a mechanical supercharger or turbocharger, will need to be able to accommodate a wide range of pressure ratios, possibly up to 2 bar of pressure boost. The mechanical pressure limits of the engine will be a more important constraint with higher levels of supercharging. The constraint on peak $\mathrm{NO}_{\mathrm{x}}$ also effects power density. Boosting the intake pressure and increasing the compression ratio decreases the quantity of a particular control variable necessary to achieve TDC combustion, i.e. less DME additive, less inlet heating, or less EGR is required. Higher compression ratio engines appear to be the best choice for an HCCI engine, particularly due to the inherent higher efficiency, although the lower compression ratio engines may better handle very low loads. Increasing heat transfer is a very important factor for determining the upper limit of compression ratio as the crevice height becomes shorter and more of the mixture is in the boundary layer. A variable compression ratio engine could allow for a wide range of loads without throttling. A fixed compression ratio machine with inlet valve timing control could be used to effectively vary the compression ratio, and with inlet and exhaust valve timing control the intake and exhaust could be effectively throttled without pumping losses.

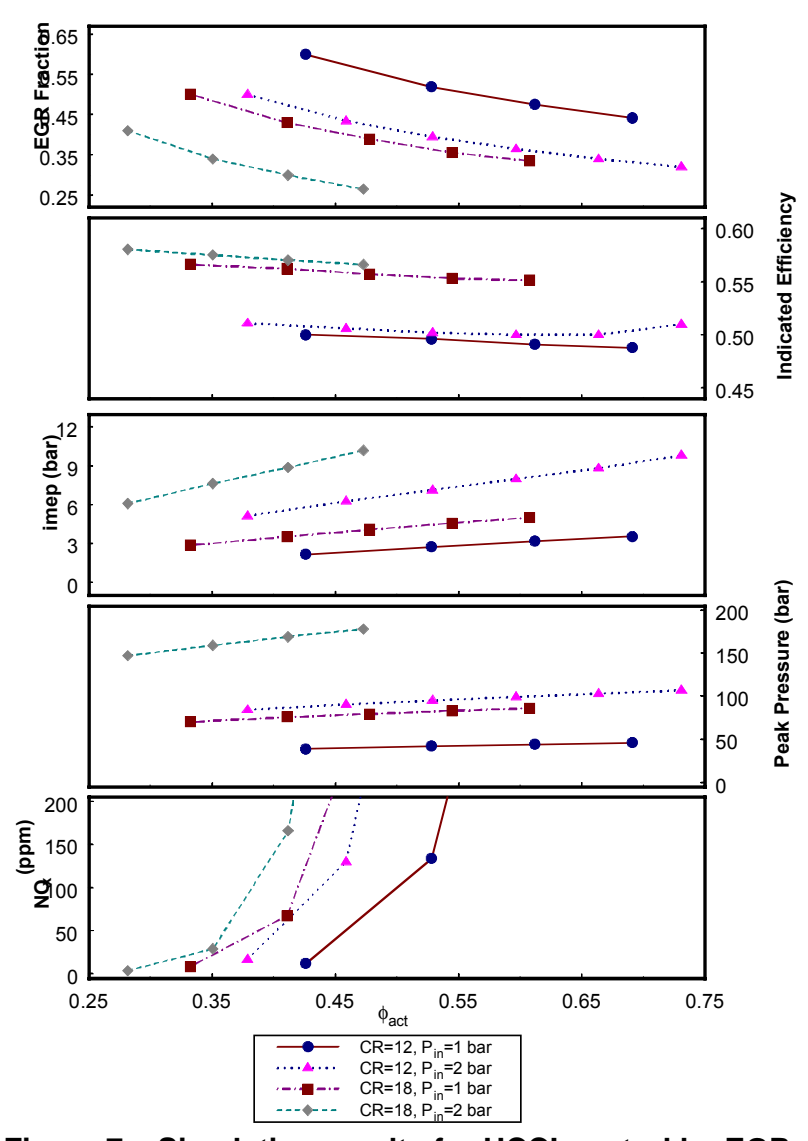

Figure 7 - Simulation results for $\mathrm{HCCl}$ control by EGR

Inlet heating allows for the greatest control of the operating range particularly at low load. Extremely lean mixtures can be ignited and very low power output can be produced. However, $\mathrm{NO}_{\mathrm{x}}$ rises very rapidly at relatively low equivalence ratio, limiting the low emission operating range. Implementation of inlet heating could require additional energy cost to power an external heater, particularly for startup. In an automotive application requiring the operator to wait for the intake air to heat up could be an unacceptable inconvenience. A DME additive scheme has potential for rapid startup because the fuel composition could be adjusted rapidly to create conditions necessary for startup. Using DME additive control may not be practical over the range of operation because it would require large quantities of both natural gas and DME to be stored. Also the DME results showed a significant amount of throttling 
required for idle. If used only for startup, only a small storage volume would be required and it could be sized for refill at a maintenance interval. An EGR-controlled engine could probably achieve reasonable peak load power with the advantage the exhaust gas is readily available in a warmed up engine, but, as with inlet heating, a startup scheme is necessary.

\section{CONCLUSIONS}

This paper presents an analysis of natural gas HCCI combustion using a detailed chemical kinetics code adapted to simulate engine conditions. Two main issues are analyzed: the effect of natural gas composition on HCCI combustion; and the use of three control methodologies for obtaining satisfactory and reliable HCCI combustion. The three control methodologies used are: addition of DME, intake gas preheat, and mixing with hot EGR. The conclusions from the analysis are:

- $\quad$ HCCI combustion is sensitive to natural gas composition, and an active control will be required to compensate for possible changes in composition. Changes in natural gas composition may shift the peak heat release timing by as much as 10 crank angle degrees. This change would have a significant effect on emissions, peak cylinder pressure, and efficiency.

- A figure of merit has been obtained that represents to a good approximation the effect of higher hydrocarbons on HCCI combustion. The figure of merit dominated by the mole fraction of propane and butane.

- The three control strategies being considered have a great effect in changing the combustion parameters for the engine, and should be able to control HCCI combustion. Optimum HCCI combustion (defined as combustion that results in maximum indicated efficiency) can be maintained over a wide range of operating conditions with these control strategies.

- The results indicate a low power output. Supercharging beyond current values ( 2 bar absolute) is necessary to achieve values comparable to those obtained from spark-ignited engines.

\section{ACKNOWLEDGMENTS}

This project is funded by DOE Office of Advanced Automotive Technologies, Steve Chalk and Lucito Cataquiz, Program Managers. Work performed under the auspices of the U.S. Department of Energy by Lawrence Livermore National Laboratory under Contract W-7405-ENG-48.

\section{REFERENCES}

Aceves, S., Smith, J. R., Westbrook, C, and Pitz, W., 1999, "Compression Ratio Effect on Methane HCCI Combustion," ASME Journal of Gas Turbines and Power, in press.

Amsden, A.A., 1993, "KIVA-3: A KIVA Program with BlockStructured Mesh for Complex Geometries," Los Alamos National Laboratory Report LA-12503-MS.
Christensen, M., Johansson, B., Amneus, P., and Mauss, F., 1998, "Supercharged Homogeneous Charge Compression Ignition," SAE Paper 980787.

Curran, H. J., Gaffuri, P., Pitz, W. J., Westbrook, C. K., and Leppard, W. R., 1995, "Autoignition Chemistry of the Hexane Isomers: An Experimental and Kinetic Modeling Study," SAE paper 952406.

Curran, H. J., Pitz, W. J., Marinov, N. M., and Westbrook, C. K., 1997, "A Wide Range Modeling Study of Dimethyl Ether Oxidation," Lawrence Livermore National Laboratory Report UCRLJC-127071.

Frenklach, M.,Wang, H., Goldenberg, M., Smith G. P., Golden, D. M., Bowman, C. T., Hanson, R. K., Gardiner, W. C., and Lissianski, V., 1995, "GRI-Mech - An Optimized Detailed Chemical Reaction Mechanism for Methane Combustion", GRI Topical Report No. GRI-95/0058.

Heywood, J. B., 1988, Internal Combustion Engine Fundamentals, McGraw-Hill, Inc., New York, NY.

Ishibashi, Y., and Asai, M., 1996, "Improving the Exhaust Emissions of Two-Stroke Engines by Applying the Activated Radical Concept," SAE Paper 960742.

Ishibashi, Y., and Asai, M., 1998, "A Low Pressure Pneumatic Direct Injection Two-Stroke Engine by Activated Radical Combustion Concept," SAE Paper 980757.

Liss, W. E., Thrasher, W. H., Steinmetz, G. F., Chowdiah, P., and Attari, A., 1992, "Variability of Natural Gas Composition in Select Major Metropolitan Areas of the United States," GRI Report NO. GRI-92/0123.

Lund, C. M., 1978 "HCT - A General Computer Program for Calculating Time-Dependent Phenomena Involving OneDimensional Hydrodynamics, Transport, and Detailed Chemical Kinetics," Lawrence Livermore National Laboratory report UCRL52504.

Miyamoto, T., Hayashi, A. K., Harada, A., Sasaki, S., Hisashi, A., and Tujimura, K., 1999, "A Computational Investigation of Premixed Lean Diesel Combustion,” SAE paper 1999-01-0229.

Najt, P. M. and Foster, D. E., 1983, "Compression-Ignited Homogeneous Charge Combustion,” SAE paper 830264.

Noguchi, M., Tanaka, Y., Tanaka, T., and Takeuchi, Y., 1979,“A Study on Gasoline Engine Combustion by Observation of Intermediate Reactive Products During Combustion," SAE paper 790840.

Onishi, S., Jo, S. H., Shoda, K., Jo, P. D., and Kato, S., 1979, "Active Thermo-Atmosphere Combustion (ATAC) - A New Combustion Process for Internal Combustion Engines," SAE paper 790501.

Pitz, W. J., Westbrook, C. K., and Leppard, W. R., 1991, "Autoignition Chemistry of C4 Olefins Under Motored Engine Conditions: A Comparison of Experimental and Modeling Results," SAE paper 912315 .

Smith, J.R., Aceves, S.M., Westbrook, C. and Pitz, W., 1997,"Modeling of Homogeneous Charge Compression Ignition (HCCI) of Methane," Proceedings of the 1997 ASME Internal 
Combustion Engine Fall Technical Conference, Paper No. 97-ICE-68, ICE-Vol. 29-3, pp. 85-90.

Suzuki, H., Koike, N., Ishii, H., and Odaka, M., 1997, "Exhaust Purification of Diesel Engines by Homogeneous Charge with Compression Ignition Part 1: Experimental Investigation of Combustion and Exhaust Emission Behavior Under Pre-Mixed Homogeneous Charge Compression Ignition Method," SAE paper 970313.

Westbrook, C. K., Warnatz, J., and Pitz, W. J., 1988, “A Detailed Chemical Kinetic Reaction Mechanism for the Oxidation of iso-Octane and n-Heptane over an Extended Temperature Range and its Application to Analysis of Engine Knock," Twenty-Second
Symposium (International) on Combustion, p. 893, The Combustion Institute, Pittsburgh.

Westbrook, C. K., Pitz, W. J., and Leppard, W. R., 1991, "The Autoignition Chemistry of Paraffinic Fuels and Pro-Knock and AntiKnock Additives: A Detailed Chemical Kinetic Study," SAE paper 912314.

Willand, J., Nieberding, R.-G., Vent, G., and Enderle, C., 1998, "The Knocking Syndrome - Its Cure and Potential," SAE paper 982483.

Woschni, G., 1967, "Universally Applicable Equation for the Instantaneous Heat Transfer Coefficient in the Internal Combustion Engine," SAE Paper 670931 
Table 1 - Fuel blends used for sensitivity analysis study

\begin{tabular}{|c|c|c|c|c|}
\hline $\mathrm{mol}^{2} \mathrm{CH}_{4}$ & $\mathrm{~mol}_{0} \mathrm{C}_{2} \mathrm{H}_{6}$ & $\mathrm{~mol}_{0} \mathrm{C}_{3} \mathrm{H}_{8}$ & $\mathrm{~mol}_{0} \mathrm{C}_{4} \mathrm{H}_{10}$ & Notes \\
\hline 100.00 & 0.00 & 0.00 & 0.00 & \\
\hline 96.50 & 3.50 & 0.00 & 0.00 & \\
\hline 93.00 & 7.00 & 0.00 & 0.00 & \\
\hline 86.00 & 14.00 & 0.00 & 0.00 & \\
\hline 98.30 & 0.00 & 1.70 & 0.00 & \\
\hline 96.60 & 0.00 & 3.40 & 0.00 & \\
\hline 93.20 & 0.00 & 6.80 & 0.00 & \\
\hline 99.30 & 0.00 & 0.00 & 0.70 & \\
\hline 98.60 & 0.00 & 0.00 & 1.40 & \\
\hline 97.20 & 0.00 & 0.00 & 2.80 & \\
\hline 94.10 & 3.50 & 1.70 & 0.70 & \\
\hline 88.20 & 7.00 & 3.40 & 1.40 & \\
\hline 76.40 & 14.00 & 6.80 & 2.80 & \\
\hline 87.15 & 7.63 & 3.70 & 1.53 & \\
\hline 84.18 & 14.59 & 0.90 & 0.34 & \\
\hline 60.43 & 2.01 & 37.30 & 0.26 & Extreme Peakshaving Blend \\
\hline 93.14 & 4.61 & 2.05 & 0.20 & Massachusettes City 2 \\
\hline 83.43 & 1.94 & 14.40 & 0.23 & Maryland Propane-Air Peakshaving \\
\hline 95.85 & 3.44 & 0.51 & 0.20 & Virginia Station A \\
\hline 93.53 & 4.69 & 1.36 & 0.42 & Ohio \\
\hline 92.92 & 4.72 & 1.64 & 0.72 & Texas City \#1 \\
\hline 91.06 & 7.62 & 1.10 & 0.22 & Colorado Station A \\
\hline 94.21 & 4.24 & 1.14 & 0.41 & California City \#1 Gate Station A \\
\hline
\end{tabular}

